\title{
Physical activity patterns, depressive symptoms and awareness of cardiovascular risk factors in postpartum women
}

\author{
Dominika Szalewska', Magdalena Skrzypkowska' \\ 1 Clinic of Rehabilitation Medicine, Medical University of Gdańsk, Poland \\ Szalewska D, Skrzypkowska M. Physical activity patterns, depressive symptoms and awareness of cardiovascular risk factors in postpartum \\ women. Ann Agric Environ Med. 2016; 23(3): 502-505. doi: 10.5604/12321966.1219195
}

\begin{abstract}
Introduction and objectives. Although physical activity has been found to reduce the risk of cardiovascular diseases and depression in the general population, little is known about physical patterns and the link with postnatal depressive symptoms and awareness of cardiovascular risk factors in postpartum women. The aim of this study was to examine physical activity patterns and their link to depressive symptoms in postpartum women. The secondary endpoint was the assessment of health awareness in women six months after delivery.

Material and methods. Eighty postpartum women with a mean age of $27 \pm 4$ years (group A -40 physically active women, group B - 40 women leading a sedentary lifestyle) completed a self-report questionnaire and The Edinburgh Postnatal Depression Scale (EPDS) questionnaire.

Results. In group A, the types of physical activity undertaken in the six-month period after delivery were as follows: 20 women - housework (180 min/session), 18 women - gentle walks (180 min/session), 16 women - group fitness classes ( $60 \mathrm{~min} / \mathrm{session})$, 6 - rapid walking (40 min/session), 3 women - swimming (60 min/session), 2 women - jogging (45 min/session), 1 woman - squash, (45 min/session) 1 - dancing (90 min/session), 1 - tennis (60min/session). Group B declared a sedentary lifestyle and physical activity of less than 30 min a day. The level of health awareness was statistically better in women who were physically active six months after delivery than in women who led a sedentary lifestyle. On a scale with a maximum 55 points, the mean scores were 47.4 in group $A$ and 31.2 in group $B(p=0.001)$. Depressive symptoms were more pronounced in group B. Twenty seven women from group A and three women from group B returned to their pre-pregnancy weight ( $p=0.04)$. Conclusions. Women who were physically active after delivery were characterized by higher health awareness and more frequent return to pre-pregnancy weight. Physical activity may be important for reducing the risk of postnatal depression.
\end{abstract}

Key words

physical activity, depressive symptoms, health awareness, postpartum

\section{INTRODUCTION}

It is well-documented that exercise contributes to health and wellbeing; however, women in general are less likely to engage in vigorous physical activity or leisure time exercise than men. Further reduction in physical activity may occur during pregnancy and in the postpartum period due to physiological changes and childcare responsibilities $[1,2]$. The implementation of physical activity in the prenatal and postpartum periods is not a routine treatment. Guidelines provided by the American College of Obstetrics and Gynecologists focus on exercise during pregnancy with little reference to physical activity after delivery [3]. It is known that physical inactivity has been identified as the fourth leading risk factor for global mortality, causing an estimated 3.2 million deaths globally. Oostpartum women are additionally at increased risk of developing postpartum depression (PPD), which is a non-psychotic depressive episode of mild to moderate severity, beginning in or extending into the first postnatal year [4]. The Edinburgh Postnatal Depression Scale (EPDS) is the most widely used screening questionnaire for PPD [5]. The scale is easy to administer, can be completed in approximately five minutes and has a simple method of scoring. Although physical activity has

Address for correspondence: Dominika Szalewska, Clinic of Rehabilitation Medicine, Medical University of Gdańsk, Marsz. F. Focha 4/46, 80-156 Gdańsk, Poland E-mail: dziel@gumed.edu.pl

Received: 20 December 2013; accepted: 29 April 2014 been found to reduce the risk of depression in the general population, little is known regarding its link with postnatal depression. Patterns of physical activity and awareness of cardiovascular risk factors are also insufficiently assessed in postpartum women.

\section{OBJECTIVE}

The aim of this study was to examine physical activity patterns and their link to depressive symptoms in postpartum women. The secondary endpoint was the assessment of health awareness in women six months after delivery.

\section{MATERIALS AND METHOD}

This was a retrospective cohort study that comprised 117 women, recruited to the study in the period 1 June - 31 October 2011. Several nurse practitioners were identified to aid in the recruitment of subjects and explain the study procedures to interested postpartum women. All the women within the six-month postpartum period were invited to complete two questionnaires. Subjects who volunteered were first asked about their physical activity habits and were then given the questionnaires. Based on responses to a short question concerning additional physical activity during the six months after delivery, the women were divided into two 
groups: group A - physically active in the postpartum period, group B - not physically active in the postpartum period, i.e. leading a sedentary lifestyle. Due to incorrect or incomplete responses in the questionnaires, data were obtained and analysed for 80 women with a mean age of $27 \pm 4$ years.

Participants also completed a questionnaire that recorded their socio-demographic factors and obstetric characteristics. The socio-demographic and obstetric risk factors questionnaire included questions on age, parity, gestational age, highest level of education completed, occupation and place of residence. In addition, the women were asked if their weight six months after delivery had returned to the prepregnancy value.

Group A contained 40 physically active women; group B contained 40 women leading a sedentary lifestyle. The participants' age structure is presented in Figures 1 and 2.

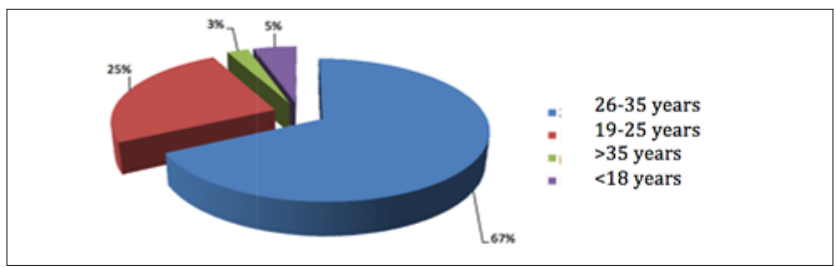

Figure 1. Age of women in group A

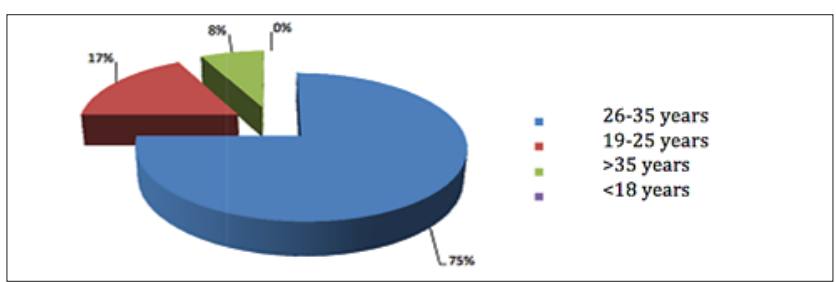

Figure 2. Age of women in group B

Written informed consent was obtained from the participants after the aims and objectives of the study had been explained. Self-reported socio-demographic characteristics of all subjects are presented in Table 1.

Table 1. Self-reported socio-demographic characteristics of all subjects $(n=80)$

\begin{tabular}{lcc}
\hline & $\begin{array}{c}\text { GROUP A } \\
\mathrm{n}=40\end{array}$ & $\begin{array}{c}\text { GROUP B } \\
\mathrm{n}=40\end{array}$ \\
\hline Age (years) (mean \pm SD) & $27 \pm 4$ & $28 \pm 5$ \\
\hline Education (\%) & 67 & 50 \\
\hline university degree & 20 & 32 \\
\hline some high school & 13 & 18 \\
\hline vocational education & & 95 \\
\hline Marital status (\%) & 90 & 10 \\
\hline married & 2 & 3 \\
\hline in partner relationship & 0 & 88 \\
\hline single & 88 & 12 \\
\hline Mode of delivery (\%) & 12 & \\
\hline vaginal & & 62 \\
\hline caesarean & 70 & 22 \\
\hline Place of residence (\%) & 15 & 8 \\
\hline city $>100,000$ inhabitants & 10 & 5 \\
\hline city $20,000-100,000$ inhabitants & 8 & \\
\hline city<20,000 inhabitants & & \\
\hline rural areas & & \\
\hline
\end{tabular}

Physical activity assessment and health awareness. The method used to survey physical activity and health awareness was a self-report questionnaire. The questionnaire concerning physical activity was composed of 24 single answer and open questions; the maximum number of points was 55 . Physical activity was defined as any bodily movement produced by skeletal muscles requiring energy expenditure. The questions were related to knowledge about a healthy lifestyle, examinations needed for the prevention of cardiovascular diseases, diet, physical activity, psychological factors leading to illnesses, and drugs. The women were also asked if their body mass had returned to their pre-pregnancy weight.

Depressive symptoms assessment. The Edinburgh Postnatal Depression Scale (EPDS) questionnaire was administered and completed by all the women. A cut-off for probable depression was established at $12 / 13$, and for possible depression at $9 / 10$ [6].

\section{RESULTS}

Demographic assessment. In group $\mathrm{A}$, the majority of women $(n=25)$ came from large cities with $>100,000$ inhabitants, nine women came from cities with 20,000100,000 inhabitants, three came from small cities with fewer than 20,000 inhabitants, and three women came from rural areas. In group B, 28 women came from large cities with $>100,000$ inhabitants, six women came from cities with 20,000-100,000 inhabitants, four came from small cities with fewer than 20,000 inhabitants and two women came from rural areas.

In all, 47 women from group A had a university degree, 21 had a high school education and 12 women had vocational education. In group B, the highest educational level was as follows: 20 - university degree, 13 - high school education, 7 - vocational education.

In group A, 38 women were married, one was living with a partner and one was single. In group B, 36 women were married, 4 were living with a partner and no-one was single. In group A, 34 women had taken a break in professional activity, five had not worked before pregnancy and one was a student and working at the same time. In group B, 25 women had taken a break in professional activity, eight had not worked before pregnancy, four were studying and working, two were university students but not working.

In both groups A and B, 35 women delivered vaginally and five by caesarean section.

Physical activity and health awareness. The main reason cited for a sedentary lifestyle in group B was the lack of need for physical activity $(\mathrm{n}=18), 10$ women gave the reason 'lack of strength', and one women reported that her doctor had forbidden physical activity in the postpartum period. The rest of the women $(n=11)$ did not engage in physical activity because of lack of time, lack of desire to exercise, or lack of interest in sport (Fig. 3).

In group $\mathrm{A}$, the patterns of physical activity in the six-month period after delivery was as follows: 20 women - housework (180 min/session), 18 women - gentle walks (180 min/session), 16 women - group fitness classes ( $60 \mathrm{~min} / \mathrm{session})$, six women - rapid walking (40 $\mathrm{min} / \mathrm{session}$ ), three women - swimming (60 min/session), two women - jogging (45 min/session), one 


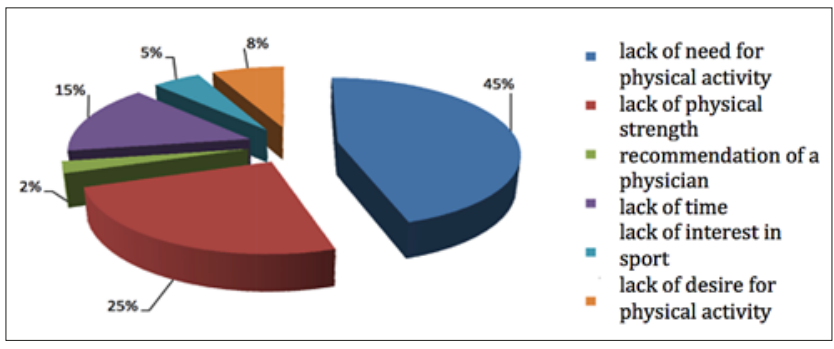

Figure 3. Reasons for physical inactivity in group B

woman - squash (45 min/session), one woman - dancing (90 $\mathrm{min} / \mathrm{session})$, one woman - tennis (60 min/session).

Health awareness was statistically better in women who were physically active in the six-month period after delivery than in women who led a sedentary lifestyle. On a scale with a maximum number of 55 points, the means were 47.4 in group A and 31.2 in group $B(p=0.001)$ (Fig. 4).

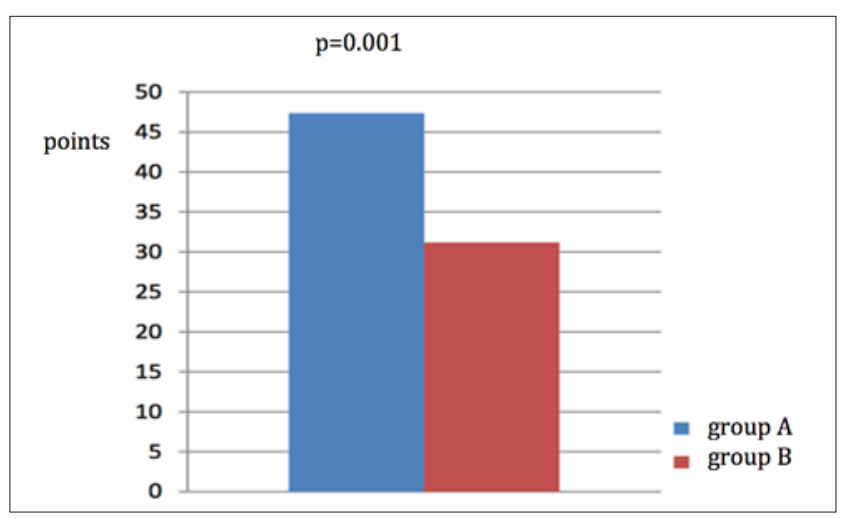

Figure 4. Level of health awareness in points

In group A, 27 women had returned to their pre-pregnancy weight, and from group B three women had done so $(\mathrm{p}=0.04)$.

Depressive symptoms. Eighty women completed the EPDS. None of them attained more than 13 points, indicating no depression in this cohort. In the 'active' group $(n=40)$, three women gained two points, five women gained one point, and in the rest of the group $(n=32)$ the result was zero. In the 'sedentary' group, two women gained three points, four women gained two points, 21 women scored one point and in 13 women the result was zero (Fig. 5).

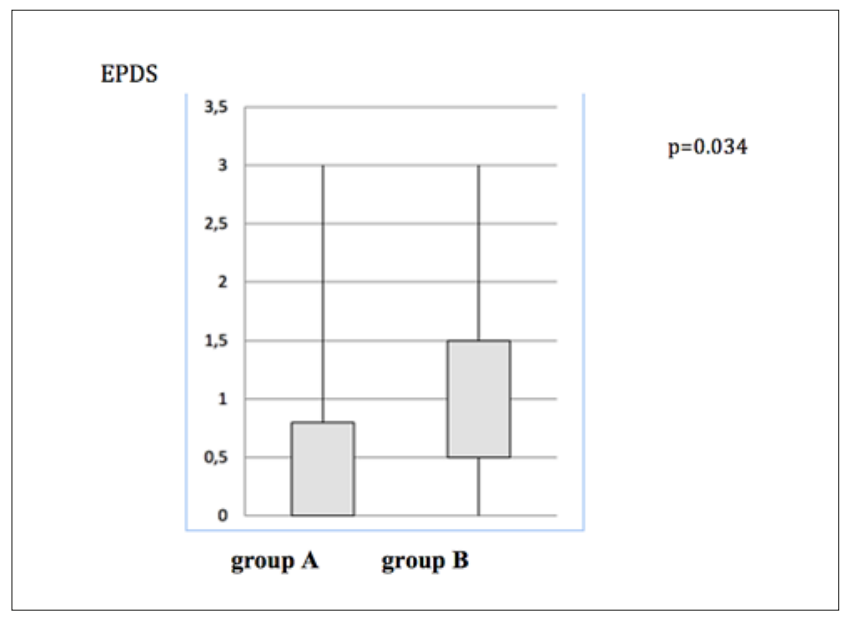

Figure 5. Depressive syptoms assessed by EPDS

\section{DISCUSSION}

Health research has demonstrated that physical activity during the postpartum period may play a crucial role in managing the physical and psychological challenges that women face during these times of transition $[7,8]$. Most studies (one cross-sectional, two longitudinal, and six intervention studies) have found an inverse association between postpartum leisure-time physical activity (LTPA) and postnatal depressive symptoms [9].

In the presented study, it was found that women who were physically active in the six-month period after delivery were more aware of cardiovascular risk factors, reported less pronounced depressive symptoms, and returned to the prepregnancy weight with greater ease than women leading a sedentary lifestyle. Awareness that a specific factor increases the risk for cardiovascular disease is positively associated with healthy behaviour regarding most risk factors, but awareness alone does not motivate behaviour [10]. Failure to return to pre-pregnancy weight by six months postpartum is associated with long-term obesity, as well as adverse health outcomes.

Historically, the postpartum period is defined as up to six weeks post-delivery, although it has been described as up to one year as a result of other pregnancy-related physiological events/changes that occur over this period (e.g. breastfeeding) [11]. Although weight retention appears to be variable, an increased body mass index (BMI) from one pregnancy to the next is associated with increased risk of multiple, serious obstetric [12] and neonatal outcomes [13, 14] during subsequent pregnancies. Moreover, failure to lose pregnancy weight by six months postpartum has been shown to be a significant predictor of long-term obesity $[15,16]$ as well as adverse health outcomes [17]. Furthermore, by the end of the first year postpartum, weight retention has been found to predict maternal overweight 15 years later [18].

Although studies are limited, on balance, both physical activity related to housework and LTPA after pregnancy may be important in reducing the risk of postnatal depression. Further research is required to determine the optimal dose and domain of physical activity for reducing postnatal depressive symptoms, as well as to examine the link between sedentary behaviour and postnatal depressive symptoms. The challenge for the medical community is to educate pregnant women on how to exercise after delivery and improve women's health awareness.

\section{CONCLUSIONS}

Women who were physically active after delivery were characterized by higher health awareness and more frequent return to pre-pregnancy weight. Physical activity may also be important for reducing the risk of postnatal depression.

\section{REFERENCES}

1. Blum JW, Beaudoin CM, Caton-Lemos L. Physical activity patterns and maternal well-being in postpartum women. Matern Child Health J. 2004 Sep; 8(3): 163-9.

2. South-Paul JE, Rajagopal KR, Tenholder MF. Exercise responses prior to pregnancy and in the postpartum state. Med Sci Sports Exerc. 1992; 24: $410-4$. 
3. American College of Obstetricians and Gynecologists. Exercise during pregnancy and the pospartum period. Obstet Gynecol. 2002; 99: 171-73.

4. Gibson J, McKenzie-McHarg K, Shakespeare J, Price J, Gray R. A systematic review of studies validating the Edinburgh Postnatal Depression Scale in antepartum and postpartum women. Acta Psychiatr Scand. 2009; 119: 350-64.

5. Boyd RC, Le HN, Somberg R. Review of screening instruments for postpartum depression. Arch Womens Ment Health. 2005; 8: 141-53.

6. Cox JL, Holden JM, Sagovsky R. Detection of postnatal depression. Development of the 10-item Edinburgh Postnatal Depression Scale. Br J Psychiatry 1987; 150: 782-6.

7. Cramp AG, Bray SR. Postnatal women's feeling state responses to exercise with and without baby. Matern Child Health J. 2010 May; 14(3): 343-9.

8. Cramp AG, Brawley LR. Sustaining self-regulatory efficacy and psychological outcome expectations for postnatal exercise: effects of a group-mediated cognitive behavioural intervention. Br J Health Psychol. 2009 Sept; 14(Pt 3): 595-611.

9. Teychenne M, York R. Physical activity, sedentary behavior, and postnatal depressive symptoms: a review. Am J Prev Med. 2013 Aug; 45(2): 217-27.

10. Alzaman N, Wartak SA, Friderici J, Rothberg MB. Effect of patients' awareness of CVD risk factors on health-related behaviors. South Med J. 2013 Nov; 106(11): 606-9.
11. Wilkinson SA,van der Pligt P, Gibbons KS, McIntyre HD. Trial for reducing weight retention in new mums: a randomised controlled trial evaluating a low intensity, postpartum weight management programme. J Hum Nutr Diet. doi:10.1111.

12. Wolfe H, Gross T. Obesity in pregnancy. Clin Obstet Gynecol. 1994; 37: 596-604.

13. Lucas A, Morley R, Cole TJ, Bamford MF, Boon A, Crowle P, Dossetor JFB, Pearse, R. Maternal fatness and viability of preterm infants. BMJ 1998; 296: 1495-7.

14. Cedergren MI, Källén BA. Maternal obesity and infant heart defects. Obes Res. 2003 Sep; 11(9): 1065-71.

15. Linne, Y, Neovius, M. Identification of women at risk of adverse weight development following pregnancy. Int J Obes. 2006; 30: 1234-9.

16. Rooney, B, Schauberger, C. Excess pregnancy weight gain and long-term obesity, one decade later. Obstet Gynecol. 2002; 100: 245-52.

17. Linne, Y, Dye L, Barkeling B, Rossner S. Weight development over time in parous women - the SPAWN study - 15 years follow up. Int J Obes Relat Metab Disord. 2003; 27: 1516-22.

18. Linne, Y, Dye, L, Barkeling, B, Rossner, S. Long-term weight development in women: a 15-year follow-up of the effects of pregnancy. Obesity. 2004; 12: 1166-78. 